Rotomahana. Lake Rotomahana is a sheet of dirty, muddy green water, some three and a half miles long by less than two miles in the opposite direction, and with a maximum depth of 427 feet. In continuation along the same line, beyond Lake Rotomahana, are the deep holes forming the Black, Fourth, Waimangu, Inferno, Echo Lake, and Southern craters. Hot water and steam issue in larger or smaller quantities from these craters, the water finding its way to Lake Rotomahana.

The most remarkable feature of the region during the last few years has been the great geyser of Waimangu. This geyser was discovered in January, 1900, and is believed to have become active only a short time before that date. While playing, outbursts occurred nearly every day, and sometimes more frequently. Mud, sand, and immense boulders were shot up in huge columns of dirty black water. At some hundreds of feet above the water the column broke, showering boulders, mud, and sand back into the pool, and even high up on the walls surrounding it.

In July, I904, the great geyser suddenly ceased, and remained dormant for seven weeks and five days; then it are being made as to the movement of underground water. A further paper on this subject has now been issued as the result of investigations made by Prof. Slichter, No. I40, on field measurements.

This paper presents an amplified exposition of the method of measuring underground water as described in his former paper of 1902. It contains descriptions of the apparatus used for the laboratory study of wells controlling horizontal and vertical movements, and the result of these studies confirms the conclusions described in the former paper as to the possibility of measuring the flow of subsurface water with trustworthy accuracy. Some improvements that have been made in the apparatus as the result of experience are described.

The author shows that the flow of water in a given direction through a column of sand is proportional to the difference in pressure at the ends of the column, and inversely proportional to the length of the column, and is also dependent upon a factor which he terms the transmission constant of the sand.

Experiment shows that the resistance to the flow of water through sand is very great, the water having to pass through pores, usually capillary in character, and the diameter of which varies from one-fourth to one-seventh of the diameter of the sand particles. When the sand is not of uniform size, and is mixed with grains slightly larger, the effect is to increase the capacity of the sand to transmit the water. Where particles seven to ten times the diameter of the original sand grains are added, each of these tends to block the course of the water. For example, a boulder placed in a mass of fine sand checks the passage of the water, and the rate of flow decreases in proportion to the number of such boulders until the amount of the large particles is equal to about 30 per cent. of the total mass. After this the flow increases until the mass of fine particles becomes negligible, and the capacity to transmit approaches that of the mass of large particles alone.

These facts are shown to have an important bearing upon the capacity of gravels to furnish water to wells, or to transmit it in the under-

FrG. r. - Highest known eruption of Wainangu. flow to rivers.

Tables are given showing the transmission constant for sands and gravels of different sizes and different degrees of porosity.

It is also shown that the rate of fiow is affected by temnerature, a change from freezing point to $75^{\circ}$ nearly doubling the power of the soil to transmit water. This paper contains a great deal of information as to the discharge from wells used for irrigation or other purposes.

Paper No. I44, by Mr. Daniel D. Jackson, deals with the normal distribution of chlorine in the natural waters of New York and New England. The author shows that, with the exception of local deposits, the normal chlorine in natural waters is derived from the salt of the ocean, blown over the land by storms, and that it diminishes in amount as the distance from the ocean increases. This decrease is so definite that equal amounts of chlorine are found along lines generally parallel to the sea coast, thus affording a basis for the establishment of isochlors. Charts and tables are given showing the proportion of chlorine at different distances from the coast. The samples were taken from ponds or open water basins as far removed from human
On a previous occasion, in NATURE of December $2 x$, 1905, we gave a short account of the investigations that

No. 1908 , vol. 74] 
habitation as possible. The charts show that the quantity of chlorine near the coast amounts to 6 parts in a million, at 4 miles away to 5 parts, at 20 miles to 3 parts, at 40 miles to I part, and at 100 miles to 0.4 part.

The fact that chlorine exists in rain water to a large extent near the sea coast was stated in the report on domestic water supply of the Rivers Pollution Commission in 1874 . It was there shown that on the coast of Devonshire, where with south-west winds sea spray is blown over the land, the amount of chlorine varies from 1.20 to $2 \cdot 10$ parts in 100,000 , and at the Land's End, with a strong south-west wind blowing, it amounts to as much as 21.8 parts. Inland the average quantity of chlorine diminishes to 0.39 part; increases to 0.99 part at Liverpool and 0.79 part at Newcastle.

Paper No. I51, by Mr. Marshall O. Leighton, deals with the field assay of water, and describes the methods which have for some time been used in connection with the investigations into the quality of water in various parts of the United States. The methods described relate, not to laboratory experiments, but to simple tests to ascertain the general character of the water by methods which can be carried out on the spot. These field determinations give the turbidity and colour of the water, the presence of chlorine, carbonates, calcium, and iron, and the amount of hardness; also the amount of suspended matter. The former are more particularly required in water for domestic supply, and the latter for that used for irrigation purposes. The amount of gradient to be given to a canal for conveying water for irrigation is governed to a great extent by the solid matter in suspension, and this also affects the capacity of the storage reservoirs. The method for determining turbidity, accompanied by an illustration of the gauge used for this purpose, was given in NATURE of January 7, 1904. A description and illustration of the Geological Survey field case is given in the paper.

Paper No. 143, by Mr. J. H. Quinton, details the experiments made under the direction of the Reclamation Department on steel concrete pipes for the purpose of determining the durability and permanence of these structures in connection with the supply of water for irrigation purposes. The pipes experimented on were 5 feet in diameter, 20 feet long, and 6 inches thick, of concrete, enclosing an armour of steel rods sufficient to resist a head of $\mathrm{I}_{5} \mathrm{o}$ feet of water with a factor of safety of 4 . The experiments showed the difficulty, even with the closest attention to the construction, of making pipes of this kind that would stand a head of roo feet.

Paper No. I50, by Mr. Robert E. Horton, gives the results of an investigation of the theory of weir measurements, and the discharge over different forms of weirs. The various coefficients of Bazin, Fteley, Stearns, and Hamilton Smith are analysed. A further description is given of the experiments performed at the Cornell University laboratory, where a closely regulated volume of water was passed over weirs of different forms placed across an experimental canal, and the results obtained compared with the different formulæ for obtaining the discharge. Tables are also given for calculating the discharge over weirs.

\section{GREENWICH OBSERVATIONS.}

$\mathrm{I} \mathrm{N}$ the introduction to the first work mentioned below, an opinion is expressed that the revision of an old catalogue must always be a source of anxiety to those who advise and undertake the revision, and that only the final result can justify the expenditure of the time and labour. Those who are responsible for this work need be under no apprehension that their efforts have been misspent. It

1 "New Reduction of Grombridge's Circumpolar Catalogue for the Epoch 18 ro-o." By F. W. Dyson. F. R.S., and W. G. Thackeray. Under the direction of $\mathrm{Sir}$ William H. M. Christie, K. C. B., F.R.S., AstronomerRoyal. (Published by order of the Board of Admiralty in obedience to
His Majesty's command. Edinburgh: Neill and Co., Ltd., ig05.) Price $24 s$.

"Telegraphic Determinations of Longitude made in the Years $1888-1902$ under the direction of Sir W. H. M. Christie, K.C. B.. F. R.S AstronomerRoyal. (Published by the Board of Admiralty in obedience to His Majesty's command. Edinburgh: Neill and Co., Ltd., rgo6.) Price $15 s$. would rather seem that in this case they have fulfilled a necessary duty, and discharged an honoured trust. It has always seemed to the writer that the ancient authorities at Greenwich were a little wanting in patriotism and enterprise in entrusting to a foreigner, however eminent, the reduction and discussion of Bradley's observations. Groombridge's observations, in a sense, may not be so completely a national possession as those of Bradley, but certainly it is not unfitting that at the Royal Observatory, almost within the shadow of which Groombridge erected his transit circle, his observations should be examined and discussed.

There are several circumstances which tend to give distinction to Groombridge's work. At the beginning of the last century his instrumental equipment was equal to, if not more powerful than, that of any other observer in Europe. The fact that, as an amateur, he gave his time and leisure to the repetition of the same mechanical performance shows that he was a lover of order and accuracy. Pond, the Astronomer Royal, whatever his failings may have been, appreciated the necessity for certainty and accuracy, and he must have impressed these qualities upon Groombridge. Further, the lapse of time, that factor which has increased the value of so much astronomical work and enhanced the reputation of so many worthies, has fought on the side of the retired West Indian merchant.

The method to be pursued in the reductions, how far the observations are to be treated as independent, how far they are to be regarded as differential, are points which must be left to the decision of the computers. They must accept the entire responsibility, since the knowledge and experience is theirs. In this case it is not impossible but that they have had the assistance of tradition. The interesting remarks of Colonel Colby and Dr. Firminger quoted by the revisers, probably do not exhaust the information at their disposal. It would be an impertinence for anyone who has not even seen the originals to offer any criticism on the methods employed by those who have gained familiarity and experience by long contact with Groombridge's figures. These methods are described with clearness and in sufficient detail, but the revisers must know so much more than they can set down.

The result is to obtain a catalogue for the equinox of 1810 of 4239 stars. The number in the original Groombridge catalogue was 4243 , but of these nine have been rejected on various grounds, and five have been added as separate stars. The places of a few more stars have been considered discordant, and have not been used in the subsequent discussion of proper motion. The accuracy of the catalogue and the care of the observer can both be estimated in some measure from the fact that a discrepancy of four seconds of arc in either right ascension or polar distance has been considered a proper limit to warrant the exclusion of the observation. The number excluded is 75 in right ascension and 214 in polar distance, slightly more than 1 per cent. of the total number of observations.

The peculiar value of this catalogue lies in the fact that its epoch is I8Io. Therefore, by comparison with modern observations, it offers the means for a new determination of the precessional constant, while the new proper motions which it makes available should give greater certainty to researches into the amount and direction of the solar motion. The length of time elapsed since Groombridge's day is not much less than that available in the case of Auwers-Bradley, and the accuracy of the observations would seem to be of the same order; but Bradley's optical means were smaller, and the average of his stars considerably brighter. Groombridge's stars include many of the ninth magnitude, and fill a gap between those to which Bradley's observations refer and the results that will be derived from photography. On the other hand, Bradley's stars were better distributed over the whole sky. Groombridge limited his observations to the circumpolar regions. Against this drawback, as against many others, the Greenwich authorities have struggled with apparent success, and a few of their final results may be given.

We have, in the first place, the proper motions of more than four thousand stars determined by comparison of places at intervals of approximately ninety years. These proper motions have been derived for the most part by a

No. I 908 , VOL. 74$]$ 